\title{
The Effects of Neural Therapy Using 1\% Procaine Injections on Pain and Autonomic Nervous System in Patients with Neck Pain
}

\author{
Rob Sillevis, PT, DPT, PhD, OCS, FAAOMPT ${ }^{1 *}$, Eric Shamus, PhD, DPT, CSCS ${ }^{2}$, Dr. Oseas Moura Filho ${ }^{3}$
}

${ }^{1,2}$ Department of Physical Therapy, Florida Gulf Coast University, Marieb Hall 428, Fort Myers, Florida 33965, United States. ${ }^{3}$ Instituto de Ensino e Pesquisa em Fisioterapia Clínica, Brazil

\author{
Article Details \\ Article Type: Research Article \\ Received date: $30^{\text {th }}$ July, 2020 \\ Accepted date: $02^{\text {nd }}$ September, 2020 \\ Published date: $07^{\text {th }}$ September, 2020
}

"Corresponding Author: Rob Sillevis, PhD, DPT, OCS, FAAOMPT, MTC, Assistant Professor, Assistant Program Director Doctor of Physical Therapy, Florida Gulf Coast University, Marieb Hall 428, Fort Myers, Florida 33965, United States. E-mail: rsillevis@,fgcu.edu

Citation: Sillevis, R., Shamus, E., \& Filho, O.M. (2020). The effects of neural therapy using $1 \%$ procaine injections on pain and autonomic nervous system in patients with neck pain. J Rehab Pract Res 1(2):111. https://doi.org/10.33790/jrpr1100111 Copyright: $\odot 2020$, This is an open-access article distributed under the terms of the Creative Commons Attribution License 4.0, which permits unrestricted use, distribution, and reproduction in any medium, provided the original author and source are credited.

\begin{abstract}
s
Background: Neural therapy, is a treatment approach that targets the nervous system by altering resting potential through injecting a local anesthetic. Neural therapy can be used to treat local tissues such as trigger points. It was the aim of this study to evaluate the short-term effect of neural therapy, using $1 \%$ procaine injections at cervicothoracic region, in subjects with chronic cervical spine pain on the autonomic nervous system. The secondary aim was to investigate if neural therapy resulted in immediate change in reported pain.
\end{abstract}

Methods: A convenience sample of 22 subjects were recruited for this study. Each subjected reported pre intervention pain level. After this they underwent an automated pupillometry measurement for 1 minute. Following this they received the neural therapy intervention paravertebrally and an immediate pupil measurement followed. A third pupillometry measure was taken 4 minutes later. After this the subject reported post intervention pain level.

Outcomes: There was no significant change in the pupil measurements in both the right and left eye $(p>0.05)$. There was a significant reduction difference in pain report post testing $(\mathbf{p}<\mathbf{0 . 0 1})$.

Discussion: The results of this study demonstrate that Neural therapy using $1 \%$ procaine has an immediate effect on localized pain perception with eight paravertebral $1 \%$ procaine injections at the level of C7-T3. No change in pupil diameter was observed following neural therapy indicating that the balance between the sympathetic and parasympathetic nervous system did not change.

Key words: Neural Therapy, Anesthetic, Pupillometry, Autonomic Nervous System

\section{Introduction}

Cervical spine disorders are common and annually create a large burden on the healthcare system totaling about 50 billion in healthcare expenditure $[1,2]$. Besides cost, it also leads to a reduced or inability to work, and a reduced work-related productivity [3, 4, 5]. Cervical spine disorders related expenditures are the second highest economic burden for musculoskeletal disorders [6]. Cervical spine pain can arise from any structure in the neck and thoracic spine including: the intervertebral disc, ligaments, muscles, facet joints, dura, and nerve roots $[7,8]$. Patients with problems originating in the cervical spine can present with pain in a variety of different symptomatic regions including: the neck, the occipital and facial areas, the shoulder and arm, and the scapulothoracic region. At any given time, approximately $10 \%$ of the adult population has neck pain [9]. Jette et al. [10] suggested that about $25 \%$ of all patients seen in outpatient physical therapy clinics present with neck pain [10]. Cervical spine pain often leads to chronic issues as up to $50 \%$ of people have pain lasting longer than 6 months [11].

Chronic pain is pain that exists beyond the normal time line of tissue healing [12]. It can involve both local and central mechanisms. In the periphery, injury may cause tissue destruction or damage resulting in activation of the peripheral nociceptors, which are present in great abundance and form a large network throughout all tissues [13-15]. Normal resting nerve cells have a resting membrane potential of approximately $70 \mathrm{mV}$ [16]. Voltage-gated sodium channels in the axon are responsible for creating and maintaining this membrane potential. Chemical mediators such as serotonin, bradykinin, and potassium are effective stimulants for nociceptors lowering this membrane potential by 30 to $40 \mathrm{mV}$, and thus decreasing the facilitation threshold $[15,17,18]$. It appears that chemical mediators that are generated in local tissues can cause a prolonged lowering of the resting action potential resulting in peripheral sensitization [1921].

Raising this resting membrane potential can have great therapeutic value and could interrupt the cascade of events leading to an maintaining chronic pain. Neural therapy, which was developed in Germany in the 1920's, is a treatment approach that targets this change in resting potential by injecting a local anesthetic [22]. Local anesthetics have been used to treat a variety of local pain generators to achieve this [23]. It has been demonstrated to be very beneficial in eliminating local trigger points $[24,25]$. While different theories exist as to the mechanism of action for local anesthetics, it is well known that these substances raise the resting membrane potential, making the nerve less likely to fire a nerve impulse even with more stimuli $[23,26]$. During the application of neural therapy, procaine is the preferred anesthetic. Procaine appears to be effective in reducing localized inflammatory processes both short and longer term [22,27]. Li et al. [27] suggested based on animal experiments that procaine is 
an effective modality to reduce nerve sensitivity. In addition, procaine has the ability to increase the refractory period (time interval between nerve firing) of the local nerve, thereby reducing the peripheral sensitization process $[22,27]$.

Chronic nociceptive information as a result of peripheral sensitization will continue to reach the spinal cord where it will result in a change in processing of central nociceptive information [28]. There will be a lowering of threshold for excitation of the inter-neurons in the spinal cord, which will result in an increased central discharge on relatively normal effective inputs and inputs that previously did not exceed facilitation threshold [29]. Because the central nervous system functions as one single unit, both the somatic and autonomic nervous system will be influenced by each other [30-32]. Several areas of interaction between the somatic and autonomic nervous system have been identified both in the periphery and centrally $[33,34]$. Therefore, in a state of central sensitization, hyperactivity is taking place at the level of nociceptive input in the spinal cord [35]. As a result, corresponding over-activity in the lateral gray matter and an expected increase in sympathetic activity will be present $[35,36]$. This means that pain has a stimulating effect on the sympathetic nervous system [37-39]. The consequences of this correlation are many and should be considered therapeutically. As an example the regulation of skeletal muscle blood flow is controlled by the sympathetic nervous system [40-43]. An increased sympathetic activity will lead to a constrictive tendency of blood vessels in the periphery [40]. If this state of increased sympathetic activity remains for a prolonged period of time ischemic changes in tissues can occur, which results in higher risk of tissue damage during the performance of normal activities and thus maintaining the cycle of chronic pain [44]. Because of this close relationship between pain and the autonomic nervous system, its parameters are often regarded as objective measures of pain in humans [45]. Several methods have been described to assess the activity of the autonomic nervous system and its components [46, 47]. The pupil of the eye is exclusively innervated by the ANS, and thus ANS activity can be measured indirectly by pupil monitoring [48-51]. The pupil dilator muscle is innervated by the sympathetic nervous system and receives its innervation through the upper cervical sympathetic ganglion. The pupil constrictor muscle is innervated by the parasympathetic nervous system with fibers originating from cranial nerve III. The diameter of the pupil at any given time is a reflection of the real time balance of between the activity of the sympathetic system and parasympathetic activity $[13,46,52]$. Previous studies have used fully automated pupillometry to capture the pupil diameter in real time [53-55].
To evaluate the short-term effect of neural therapy in subjects with chronic cervical spine pain, the aim of this pilot study was twofold. The primary aim was to investigate if segmentally applied neural therapy using $1 \%$ procaine injections at cervicothoracic region has a systemic effect on the autonomic nervous system. The secondary aim was to investigate if neural therapy resulted in immediate change in reported pain.

\section{Material and Methods \\ Subjects}

Because this was a pilot study, we did not perform a power analysis. We recruited a convenience sample of 22 adult subjects for this pilot study in September 2019 during the 11 Congresso International de Fisioterapia, Salvador, Brazil. All available subjects were screened for eligibility criteria. To participate, all subjects had to be between the ages of 18 and 65 , able to speak and read the Spanish language fluently, have chronic neck pain, and experience pain at the time of testing. The subjects were screened for any red flags and potential reasons why they could not undergo the procaine injection protocol by the treating physical therapist. Additional exclusion criteria included: use of blood thinning medications, history of surgery and or injury within the past six weeks, or evidence of central nervous system involvement, including hyperreflexia, sensory disturbances in the hand, intrinsic muscle-wasting of the hands, unsteadiness while walking, nystagmus, loss of visual acuity, impaired sensation of the face, altered taste, and the presence of pathological reflexes. All subjects provided written consent prior to participating in the study.

\section{Automated measures}

To obtain a measure of autonomic nervous system activity, the pupil diameter can be measured directly in real time $[49,51,52,56-$ 58]. In this study, the pupil responses were measured with the fully automated Vorteq ${ }^{\circledR}$ system (Micromedical Technologies, Inc) to record the pupil reaction. To control for any light affecting the pupil measures, the subjects wore goggles that covered both eyes to create a completely dark environment. In the dark, the activity of the parasympathetic nervous system is greatly reduced and, therefore, an increase in pupil diameter indicates a relatively unopposed activation of the sympathetic nervous system [13, 58, 59]. Infrared cameras are built into the goggles, allowing for direct measurement of the pupil diameter of the both eyes simultaneously (Figure 1).

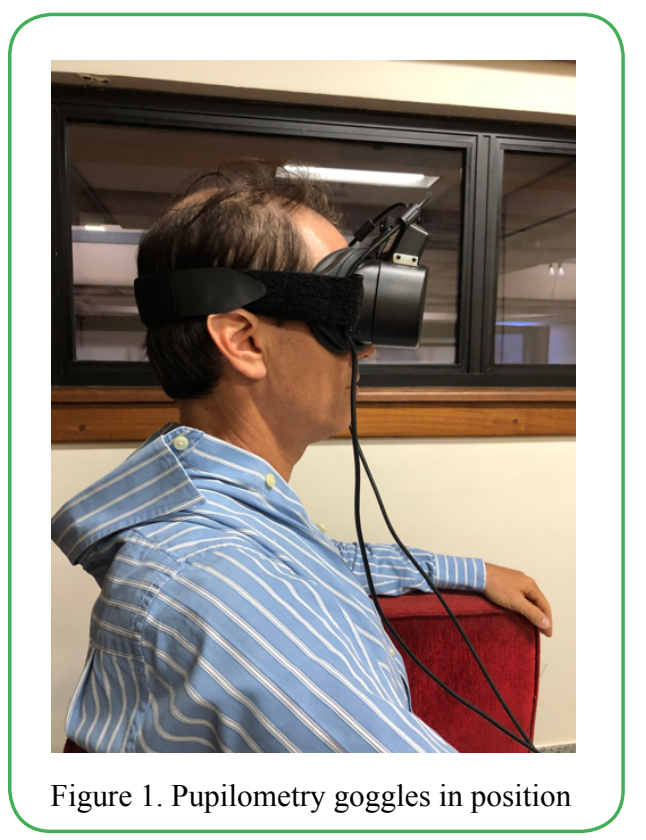


Fully automated pupillometry devices have been used previously in a number of studies investigating autonomic nervous system activity $[48,51,54,55,60-65]$. The measurement error is minimal and pupil changes of less than $0.2 \mathrm{~mm}$ can be detected [63, 65-67]. Intra-rater repeatability of automatic pupillometric devices is strong, with the coefficient of repeatability ranging from 0.6 to $1.4 \mathrm{~mm}[60,61]$. Both the sensitivity and reliability of the pupillometry to evaluate the autonomic nervous system have been shown previously [48, 68-70].

\section{Study Protocol}

After providing consent, all subjects rated their current pain level on a Numeric Pain Rating Scale (NPRS). Each subject underwent the same protocol to consistently identify the localization of the paravertebral needle placement. In all participants, C7 was identified as the vertebrae with the largest spinous process, and C6 was identified as the spinous process that would nearly disappear upon motion that extends the cervical spine while seated [71, 72]. Passive neck flexion was used to identify inter-segmental motion in order to determine the T3-T4 level [73]. A mark was placed on the skin identifying the $\mathrm{T} 3$ spinous space process, allowing for easy identification during the intervention.

\section{Measurement Position}

During the measurement phase, all subjects were seated in a comfortable position with the arms on their laps. This position was chosen to allow the goggles to be worn comfortably and to guarantee that cameras would be able to capture the pupil during the measurement protocol without difficulty. All subjects remained in complete darkness, created by the goggles, for the duration of the intervention and measurement protocol. The subjects confirmed verbally that no light was entering the goggles. The darkness allowed for a constant maximum pupil diameter during the pupil measurement without the influence of light [74].

\section{Measurement/needling protocol}

After two minutes of accommodation to the dark environment, the pupils were measured continuously for a 60 -second duration. Directly following the baseline measurement, the subject received neural therapy with eight paravertebral $1 \%$ procaine injections at the level of C7-T3 (Figure 2). In order to achieve consistent needle placement between subjects, the needles were placed at a distance of two fingers lateral to the spinous process. The needle was inserted fully at a 45-degree angle toward the spine. This same needle placement protocol was previously reported by Sillevis et al. [55].

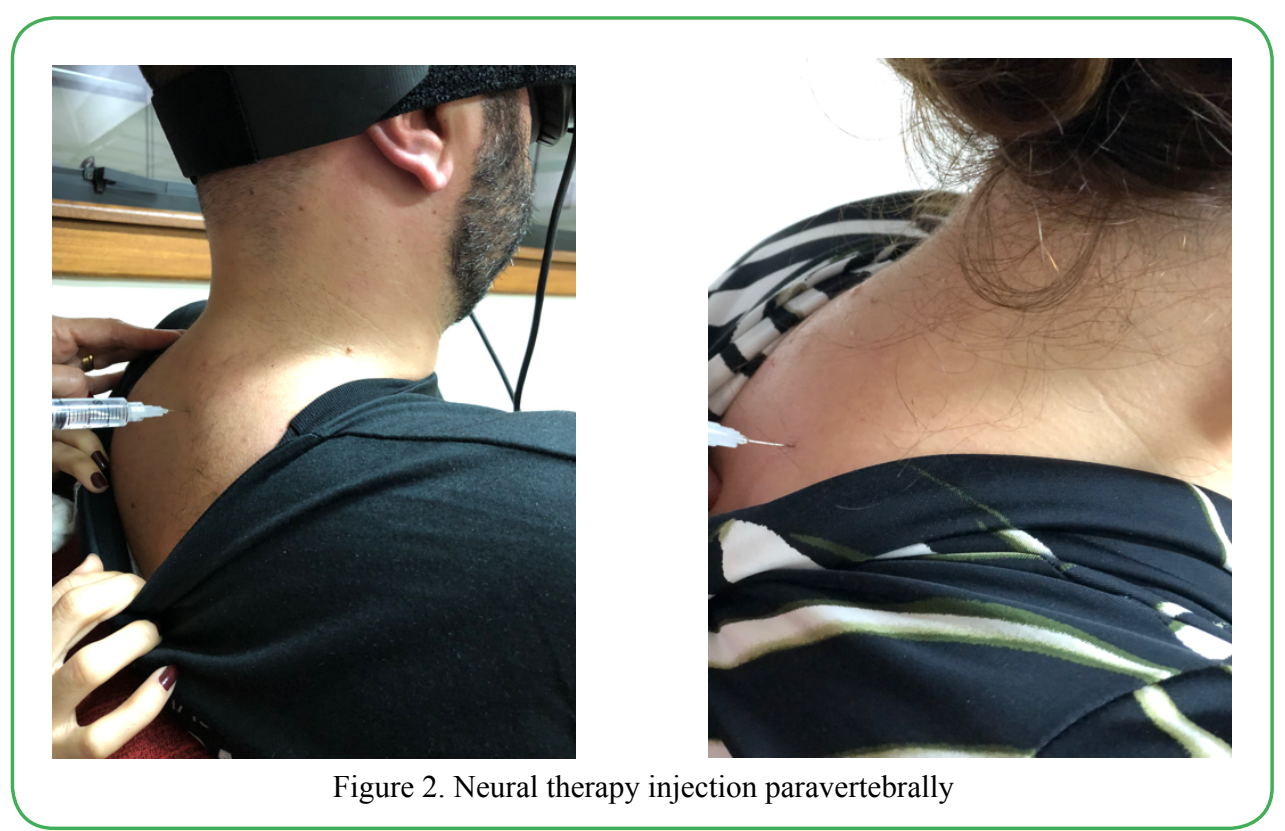

Directly following the needle placement, a continuous pupil measurement of both eyes was performed for 60 seconds. After a 3 -minute period, the third and final 60 -second pupil measurement was taken, which completed the measurement phase. The subjects reported their 5-minute post intervention pain level on a NPRS scale. The testing environment was temperature-controlled and remained the same for all subjects during this pilot study.

\section{Statistical analysis}

Statistical analyses were performed using the SPSS, version 26.0, statistical software package. We analyzed the data for normal distribution using the Sharpo-Wilk test. All data were normally distributed so the repeated measure ANOVA was used to analyze the data.

\section{Baseline characteristics}

A total of 23 subjects were assessed for eligibility and enrolled in the study. One subject filled out the paperwork and pretesting measures but never returned for the intervention and pupillometry measures. Hence, 22 subjects completed the full testing protocol. Ten subjects were male while twelve were female, and the mean subject age was 35.5 years, with a range of 20 to 55 years.

\section{Systemic effect of the neural therapy using $1 \%$ procaine injections}

To determine the immediate effect of segmentally applied $1 \%$ procaine injections on the ANS, the pupil diameter was compared prior to the intervention with the pupil measurement taken immediately after the injections (Post1) and 4 minutes later (Post2). The assumptions for the use of parametric statistics was satisfied. Thus, we employed the repeated measure ANOVA test to compare the pre- and post-needling pupil diameter. The pupil diameter mean for each of the measures for both eyes are reported in Table 1 .

The repeated measure ANOVA with a Greenhouse-Geisser correction showed that the mean pre-pupil diameter of the left eye did not differed significantly between Post 1 and Post 2 measures $(\mathrm{F}=$ $2.662, \mathrm{p}=0.104$ ). This test yielded an observed power of 0.41 . The repeated measure ANOVA with a Greenhouse-Geisser correction evaluating the mean pre-pupil diameter of the left eye relative to gender did not differed significantly between Post 1 and Post2 measures $(\mathrm{F}=1.78, \mathrm{p}=0.193)$. This test yielded an observed power of 0.29 .

The repeated measure ANOVA with a Greenhouse-Geisser correction showed that the mean pre-pupil diameter of the right eye did not differed significantly between Post 1 and Post 2 measures 


\begin{tabular}{|c|c|c|c|c|}
\hline & \multirow{2}{*}{$\begin{array}{l}\mathrm{N} \\
\text { Statistic }\end{array}$} & \multicolumn{2}{|c|}{ Mean } & \multirow{2}{*}{$\begin{array}{l}\text { Std. Deviation } \\
\text { Statistic }\end{array}$} \\
\hline & & Statistic & Std. Error & \\
\hline GRCS & 22 & 3.2273 & .41053 & 1.92556 \\
\hline age & 22 & 35.5000 & 2.28561 & 10.72047 \\
\hline NASpre & 22 & 2.9545 & .52421 & 2.45875 \\
\hline NASpost & 22 & 1.3636 & .41895 & 1.96506 \\
\hline Pre_L & 22 & 107.1068 & 4.50064 & 21.10989 \\
\hline Pre_R & 22 & 120.4286 & 7.92713 & 37.18156 \\
\hline Post1_L & 22 & 108.1909 & 4.62668 & 21.70103 \\
\hline Post1_R & 22 & 118.5159 & 6.70901 & 31.46804 \\
\hline Post2_L & 22 & 115.9764 & 7.21954 & 33.86265 \\
\hline Post2_R & 22 & 125.8774 & 9.80207 & 45.97579 \\
\hline gender & 22 & 1.5455 & .10866 & .50965 \\
\hline
\end{tabular}

$(\mathrm{F}=0.692, \mathrm{p}=0.42)$. This test yielded an observed power of 014 . The repeated measure ANOVA with a Greenhouse-Geisser correction evaluating the mean pre-pupil diameter of the left eye relative to gender did not differed significantly between Post1 and Post2 measures $(\mathrm{F}=1.21, \mathrm{p}=0.30)$. This test yielded an observed power of 0.21 .

\section{Change in self-reported pain levels}

To determine the immediate effect of segmentally applied $1 \%$ procaine injections on the self-report of pain we compared the NPRS pretesting to the NPRS immediately 5-minute post testing. The Paired sample $t$ test was used. There was a significant reduction difference in pretesting reported pain $(\mathrm{M}=2.95, \mathrm{SD}=2.46)$ and the post testing score $(\mathrm{M}=1.36, \mathrm{SD}=1.97) ; \mathrm{t}(21)=7.406, \mathrm{p}<0.01$. (Table 2$)$

\begin{tabular}{|l|l|l|l|l|l|l|l|l|}
\hline \multicolumn{7}{|c|}{ Paired Samples Statistics } \\
\hline & & Mean & N & Std. Deviation & Std. Error Mean \\
\hline Pair 1 & NASpre & 2.9545 & 22 & 2.45875 & .52421 \\
\cline { 2 - 8 } & NASpost & 1.3636 & 22 & 1.96506 & .41895 \\
\hline \multicolumn{7}{|c|}{$\begin{array}{l}\text { Paired Samples Test } \\
\text { Paired Differences }\end{array}$} \\
\hline
\end{tabular}

\section{Global Rating of Change Scale}

Each subject completed a Global Rating of Change Scale using a 5 point Likert scale ( -5 indicating "very much worse", 0 indicating "no change", and 5 indicating "Completely gone") The mean score was 3.22 ( $\mathrm{SD}=1.92)$ supporting the hypothesis of an overall selfperceived benefit from the intervention on their pain experience.

\section{Discussion}

The aim of this pilot study was to evaluate the immediate shortterm effect of the paravertebral application of neural therapy using $1 \%$ procaine at the cervicothoracic region in subjects with chronic neck pain was on the autonomic nervous system. Additionally, it set out to investigate the immediate self-perceived changes in pain following neural therapy. The results of this study demonstrate that neural therapy did not had have an immediate short-term systemic effect on the ANS.

Neural Therapy is an approach to change the local resting potential of nerve cells by introducing a local anesthetic, such as procaine. Due to local disturbances this resting potential drops to about $45 \mathrm{mV}$. The lower threshold creates chronic low-grade excitation, impaired intracellular metabolism and ion exchange, and persistent inability to maintain a normal resting potential, results in chronic neurophysiologic instability $[15,17,18]$. This makes the nerve cell more susceptible to stimulation. It has been proposed that Neural therapy is an approach to treat disturbances of the autonomic nervous system [22]. This can be achieved by segmental therapy where a local anesthetic is introduced to the cutaneous branches of the of the deeper autonomic nerves. This will increase its resting potential and refractory period and thus irritability. We used automated pupillometry to measure the pupillary response the segmental application of neural therapy. Previous research has validated pupillometry as a reliable method of assessing the autonomic nervous system without the presence of examiner bias $[48,49,58,60,61,63,66,67,75,76]$. The innervation of the dilator pupillae muscle is sympathetic [52]. The sympathetic nerve fibers originate in the superior cervical ganglion and reach the dilator pupillae muscle through the trigeminal nerve [13, 46, 52]. The superior ganglion receives its sympathetic secondary neuron from the gray horn of C8-T3 [32]. For this reason, we applied the neural therapy paravertebrally at the $\mathrm{C} 7-\mathrm{T} 3$ segments. It was previously demonstrated that paravertebral dry needling in these segments leads 
to a change in pupil diameter due to a significant increase in activity of the sympathetic nervous system lasting up to about 18 minutes [55]. The results of this study cannot support the premise that application of neural therapy had a systemic effect on the autonomic nervous system. This finding might be because the application of the $1 \%$ procaine prevented this shift in functioning of the autonomic nervous system. It could also be possible that there was a localized autonomic effect, which would not have been detected by pupillometry. These localized effects seem to occur regardless of what is injected and are even reported with the use of a dry needle. Haker et al. [77]. reported a change in autonomic baseline parameters after the use of needling in the hand and Sandberg et al. [78] demonstrated increased blood flow in the skin and muscles directly after needling.

The introduction of any needle to penetrate the skin will affect the underlying connective tissue and neuromuscular system with or without the use of any anesthetic. Although the exact mechanism by which it works remains unknown, needling has many proposed clinical benefits [79]. These effects include reductions in local and central pain, biomechanical changes, vascular effects, and local muscle twitch responses changing active trigger point activity [8084]. The results of this study support the hypothesis that neural therapy using $1 \%$ procaine has an immediate effect on localized pain perception and subject were able to identify that something had positively changed after the treatment. This is consistent with other reports where the introduction of needles in localized tissue led to an immediate increase pain threshold and ROM, decrease muscle tone, and decrease pain [82, 85-87]. One limitation of this study was the fact that subject pain response was assessed immediately 5-minutes after the injection and there might not have a long term pain reduction effect.

In order for nociceptive information to result in pain awareness, the central nervous system will have to recognize either direct tissue trauma and potential threat to the body $[14,88,89]$. This assumption concurs with the finding reported by Wang et al. [90] that regardless of the diameter of the needle used to penetrate the skin, some pain will be experienced as a result of the needle penetration. Soreness after injections is reported as a common side effect. Researchers have previously suggested that this soreness results from neuromuscular tissue damage, possible bleeding of blood vessels, and an initial inflammatory response [91, 92]. These findings support our observation of an overall increase in pupil diameter after needle placement, although not significant. What is not clear by this study is why we observed an increased sympathetic activity and the subjects reported decreased pain levels. The localized introduction of $1 \%$ procaine likely played a role in this decreased localized perception of pain and it could be that the more systemic changes in autonomic nervous system would have taken longer to be achieved and thus was missed due to our measurement protocol.

To our knowledge, this study is the first study that has attempted to measure the autonomic nervous system effect of a segmental application of neural therapy. Although we can support the immediate effect of neural therapy on the pain experience, it did not create a significant measurable systemic change in autonomic nervous system functioning. The results of this pilot study identify that additional research is needed to determine if a systemic effect of the autonomic nervous system occurs after a longer period of time. The design of this pilot study has several limitations. First, it had a small subject sample, which limits the generalizability of the findings. Additionally, gender representation was not equal, as the subject sample included 10 males and 12 females. However, it is unlikely to have negatively affected the outcome of this study, since it was previously demonstrated that there seems to be no gender difference in pupil response for low levels of painful stimuli [93]. Ellermeier and Westphal [93] found no gender difference in pupil response for low levels of painful stimuli which is supported by the findings of this study. Although the practitioners applying the neural therapy in our subjects had a significant amount of experience the initial needle penetration certainly could have contributed to the sympathetic responses that we observed in our subjects. We did not control for this potential issue. The subjects of this pilot study were selected based on the presence of neck pain. The subjects reported a mean NPRS of 3.0. The results of this pilot study could be different in subjects with higher levels of NPRS and or different pain conditions, which should be considered in follow-up studies. Additionally, the inclusion criteria did not control for substances that could have an effect on the autonomic nervous system. This was intentional because one cannot control this in patients either. We have to consider that this might have affected the study results.

\section{Conclusion}

Neural therapy using $1 \%$ procaine has an immediate effect on localized pain perception with eight paravertebral $1 \%$ procaine injections at the level of C7-T3. What is not clear by this study is why an increased sympathetic activity was observed and the subjects reported decreased pain levels.

Conflicts of interest/Competing interests: Authors report no conflict or competing interest.

\section{References}

1. Strine, T., \& Hootman, J. (2007). US National Prevelance and Correlations of Low Back and Neck Pain Among Adults. Arthritis \& Rheumatism (Arhtritis Care \& Research), 57(4), 656-665.

2. Taylor, H., \& Murphy, B. (2008). Altered Sensorimotor Integration With Cervical Spine Manipulation. Journal of Manipulative and Physiological Therapeutics, 31(2), 116-125.

3. Gross, A., Hoving, J., Haines, T., Goldsmith, C., Kay, T., Aker, P., \& Bronfort, G. (2004). A Cochrane Review of Manipulation and Mobilization for Mechanical Neck Disorders. Spine, 29(14), 1541-1548.

4. Gross, A., Kay, T., Hondras, M., Goldsmith, C., Haines, T., Peloso, P., ... Hoving, J. (2002). Manual therapy for mechanical neck disorders: a systematic review. Manual Therapy, 7(3), 131149.

5. Tseng, Y., Wang, W., Chen, W., Hou, T., Chen, T., \& Lieu, F. (2006). Predictors for immediate responders to cervical manipulation in patients with neck pain. Manual Therapy, 11, 306-315.

6. Cleland, J. A., Childs, J. D., McRae, M., Palmer, J. A., \& Stowell, T. (2005). Immediate effects of thoracic manipulation in patients with neck pain: a randomized clinical trial. Man Ther, 10(2), 127-135.

7. Bogduk, N. (1994). Innervation and Pain patterns of the Cervical Spine. In Clinics in Physical Therapy: Physical Therapy of the Cervical and Thoracic Spine (pp. 65-76). New York: Churchill Livingstone.

8. Krauss, J., Creighton, D., Ely, J., \& Podlewska-Ely, J. (2008). The Immediate Effects of Upper Thoracic Translatoric Spinal Manipulation on Cervical Pain and Range of Motion: A Randomized Clinical Trial Journal of Manual and Manipulative Therapy, 16(2), 93-99.

9. Najm, W., Seffinger, M., Mishra, S., Dickerson, V., Adams, A., Reinsch, S., . . G Goodman, A. (2003). Content validity of manual spinal palpatory exams- A systematic review. BMC Musculoskeletal Disorders, 3, 1-14.

10. Jette, A., Simth, K., Haley, S., \& Davis, K. (1994). Physical Therapy Episodes of Care for Patients With Low Back Pain. Physical Therapy, 74(2), 101-115. 
11. Blanpied, P. R., Gross, A. R., Elliott, J. M., Devaney, L. L., Clewley, D., Walton, D. M., . . . Robertson, E. K. (2017). Neck Pain: Revision 2017. J Orthop Sports Phys Ther, 47(7), A1-A83. doi:10.2519/jospt.2017.0302

12. Boswell, M., Shah, R., Everett, C., Sehgal, N., MckenzieBrown, A., Abdi, S., . . Manchikanti, L. (2005). Interventional Techniques in The Management of Chronic Spinal Pain: Evidence-Based Practice Guidelines. Pain Physician, 8, 1-47.

13. Bernards, J., \& Bouman, L. (1988). Fysiologie van de mens. Utrecht: Bohn, Scheltema \& Holkema.

14. Coutaux, A., Adam, F., Willer, J., \& Le Bars, D. (2005). Hyperalgesia and allodynia: peripheral mechanisms. Joint Bone Spine, 72, 359-371.

15. Cyriax, J. (1982). Textbook of orthopaedic Medicine, Volume one Diagnosis of Soft Tissue Lesions (8th ed.). London: Bailliere Tindall.

16. Santos-Sacchi, J. (1993). Voltage-dependent ionic conductances of type I spiral ganglion cells from the guinea pig inner ear. J Neurosci, 13(8), 3599-3611.

17. Bendtsen, L. (2003). Central and Peripheral Sensitization in Tnesion-type Headaches. Current Headache Reports, 2, 460-465.

18. Millan, M. (2002). Descending control of pain. Progress in Neurobiology, 66, 355-474.

19. Curatolo, M., Arendt-Nielsen, L., \& Petersen-Felix, S. (2004). Evidence, Mechanisms, and Clinical Implications of Central Hypersensitivity in Chronic Pain After Whiplash Injury. Clinical Journal of Pain, 6(November/December), 469-476.

20. Kingery, W., Guo, T., Davies, M., Limbird, L., \& Maze, M. (2000). The $x 2 \mathrm{a}$ adrenoceptor and the sympathetic postganglionic neuron contribute to the development of neuropathic heat hyperalgesia in mice. Pain, 85, 345-358.

21. Sluka, K., Price, M., Breese, N., Stucky, C., Wemmie, J., \& Welsh, M. (2003). Chronic hyperalgesia induced by repeated acid injections in muscle is abolished by the loss of ASIC3, but not ASIC1. Pain, 106, 229-239.

22. Fleckenstein, J., Konig, M., \& Banzer, W. (2018). Neural therapy of an athlete's chronic plantar fasciitis: a case report and review of the literature. J Med Case Rep, 12(1), 233. doi:10.1186/ s13256-018-1770-4

23. Lirk, P., Picardi, S., \& Hollmann, M. W. (2014). Local anaesthetics: 10 essentials. Eur J Anaesthesiol, 31(11), 575-585. doi:10.1097/EJA.0000000000000137

24. Byrn, C., Borenstein, P., \& Linder, L. E. (1991). Treatment of neck and shoulder pain in whip-lash syndrome patients with intracutaneous sterile water injections. Acta Anaesthesiol Scand, 35(1), 52-53. doi:10.1111/j.1399-6576.1991.tb03240.x

25. Kern, U., Martin, C., Scheicher, S., \& Muller, H. (2003). [Treatment of phantom pain with botulinum-toxin A. A pilot study]. Schmerz, 17(2), 117-124. doi:10.1007/s00482-0030202-5

26. Joyce, P. I., Atcheson, R., Marcus, R. J., Heffernan, A. M., Rowbotham, D. J., \& Lambert, D. G. (2001). Interaction of local anaesthetic agents with the endogenous norepinephrine transporter in SH-SY5Y human neuroblastoma cells. Neurosci Lett, 305(3), 161-164. doi:10.1016/s0304-3940(01)01822-5

27. Li, D., Yan, Y., Yu, L., \& Duan, Y. (2016). Procaine Attenuates Pain Behaviors of Neuropathic Pain Model Rats Possibly via Inhibiting JAK2/STAT3. Biomol Ther (Seoul), 24(5), 489-494. doi:10.4062/biomolther.2016.006

28. Staud, R., Vierck, C., Cannon, R., Mauderli, A., \& Price, D. (2001). Abnormal sensitization and temporal summation of second pain (wind-up) in patients with fibromyalgia syndrome. Pain, 91, 165-175.
29. Woolf, C., \& Doubell, T. (1994). The pathophysiology of chronic pain-increased sensitivity to low threshold Abeta-fibre inputs. Current Opinion in Neurobiology, 4(525-534).

30. Barman, S., \& Wurster, R. (1978). Interaction of descending spinal sympathetic pathways and afferent nerves. American Journal of Physiology, 234(3), H223-H229.

31. Benarroch, E. (2006). Pain-autonomic interactions. Neurological sciences, 27(Suppl 2), S130-S133.

32. Van Cranenburgh, B. (1989b). Inleiding in the toegepaste neurowetenschappen (Vol. 1). Lochem: Uitgeversmaatchappij de Tijdstroom.

33. Benarroch, E. (2001). Pain-autonomic interactions: a selective review. Clinical Autonomic Research, 11, 343-349.

34. Zusman, M. (2002). Forebrain-mediated sensitization of central pain pathways: 'non-specific' pain and a new image for MT. Manual Therapy, 7(2), 80-88.

35. Sato, A. (1972). Somato-Sympathetic Reflex Discharges Evoked through Supramedullary Pathways. Pflugers Arch., 332, 117-126.

36. Sato, A. (1997). Neural Mechanisms of Autonomic Responses Elicted by Somatic Stimulation. Neuroscience and Biobehavioral Physiology, 27(5), 610-621.

37. Kawasaki, A. (1999). Physiology, assessment, and disorders of the pupil. Current Opinion in Opthalmology, 10, 394-400.

38. Loewenfeld, I., \& Newsome, D. (1971). Iris Mechanics I. Influance of pupil size on dynamics of pupillary movements. American Journal of Ophthalmology, 71(1), 347-362.

39. Yang, L., Niemann, C., \& Larson, M. (2003). Mechansim of Pupillary Reflex Dilation in Awake Volunteers and in Organ Donors. Anesthesiology, 99(6), 1281-1286.

40. Rowell, L. (1997). Neural Control of Muscle Blood Flow: Importance During Dynamic Exercise. Clinical and Experimental Pharmacology and Physiology, 24, 117-125.

41. Segal, S. (1994). Cell-to-cell communication coordinates blood flow control. Hypertension, 23, 1113-1120.

42. Segal, S. (2005). Regulation of Blood Flow in the Microcirculation. Microcirculation, 12, 33-45.

43. Thomas, G., \& Segal, S. (2004). Neural control of muscle blood flow during exercise. Journal of Applied Physiology, 97, 731738.

44. Maguire, A., Craig, M., Craighead, A., Chan, A., Cusumano, J., Hing, S., . . . Donaghue, K. (2007). Autonomic Nerve Testing Predicts the Development of Complications. Diabetes Care, 30(1), 77-82.

45. Vicenzino, B., Collins, D., \& Wright, T. (1994). Sudomotor Changes Induced by Neural Mobilisation Techniques in Asymptomatic Subjects. The Journal of Manual \& Manipulative Therapy, 2(2), 66-74.

46. Butler, D. (2000). The Sensitive Nervous System. Adelaide, Australia: Noigroup Publications.

47. Menck, J., Requejo, S., \& Kulig, K. (2000). Thoracic Spine Dysfunction in Upper Extremity Complex Regional Pain Syndrome Type I. Journal of Orthopaedic \& Sports Physical Therapy, 30(7), 401-409.

48. Bertinotti, L., Pietrini, U., Del Rosso, A., Casale, R., Colangelo, N., Zoppi, M., \& Matucci-Cerinic, M. (2002). The Use of Pupillometry in Joint and Connective Tissue Diseases. New York Academy of Sciences, 966, 446-455.

49. Bitsios, P., Prettyman, R., \& Szabadi, E. (1996). Changes in Autonomic Function with Age: A Study of Pupillary Kinetics in Healthy Young and Old People. Age and Ageing, 25, 432-438. 
50. Capao Filipe, J., Falcao-Reis, F., Castro-Correia, J., \& Barros, H. (2003). Assessment of autonomic function in high level athletes by pupillometry. Autonomic Neuroscience: Basic and Clinical, 104, 66-72.

51. Fotiou, F., Fountoulakis, K., Goulas, A., Alexopoulos, L., \& Palikaras, A. (2000). Automated standardized pupillometry with optical method for purposes of clinical practice and research. clinical physiology, 20(5), 336-347.

52. Gibbons, P., Gosling, C., \& Holmes, M. (2000). Short-Term Effects of Cervical Manipulation on Edge Light Pupil Cycle Time: A Pilot Study. Journal of Manipulative and Physiological Therapeutics, 23(7), 465-469.

53. Sillevis, R., \& Cleland, J. (2011). Immediate effects of the audible pop from a thoracic spine thrust manipulation on the autonomic nervous system and pain: a secondary analysis of a randomized clinical trial. J Manipulative Physiol Ther, 34(1), 37-45. doi:S0161-4754(10)00330-1 [pii] 10.1016/j. jmpt.2010.11.007

54. Sillevis, R., Cleland, J., Hellman, M., \& Beekhuizen, K. (2010). Immediate effects of a thoracic spine thrust manipulation on the autonomic nervous system: a randomized clinical trial. J Man Manip Ther, 18(4), 181-190. doi:10.1179/10669811 0X12804993427126

55. Sillevis, R., Van Duijn, J., Shamus, E., \& Hard, M. (2019). Time effect for in-situ dry needling on the autonomic nervous system, a pilot study. Physiother Theory Pract, 1-9. doi:10.1080/09593 985.2019.1644691

56. Dutsch, M., Hilz, M., Raunhut, U., Solomon, J., Neundorfer, B., \& Axelrod, F. (2002). Sympathetic and parasympathetic pupillary dysfunction in familial dysautonomia. Journal of Neurological Sciences, 195, 77-83.

57. Harle, D., Wolffsohn, J., \& Evans, B. (2005). The pupillary light reflex in migraine. Ophthal. Physiol. Opt, 25(3), 240-245.

58. Pfeifer, M., Cook, D., Brodsky, J., Tice, D., Parrish, D., Reenan, A., ... Porte, D. (1982). Quantitative Evaluation of Sympathetic and Parasympathetic Control of Iris Function. Diabetes Care Diabetes Care, 5(5), 518-528.

59. Bakes, A., Bradshaw, M., \& Szabadi, E. (1990). Attentuation of the pupillary light reflex in anxious patients. Br. J. clin. Pharmac., 30, 377-381.

60. Boxer Walcher, B., \& Krueger, R. (1999). Agreement and Repeatability of Infrared Pupillometry and the Comparison Method. Ophthalmology, 106(2), 319-323.

61. Boxer Walcher, B., \& Krueger, R. (2000). Agreement and repeatability of pupillometry using videokeratography and infrared devices. Journal of Cataract Refract Surg, 26(January), $35-40$.

62. Levy, D., Rowley, D., \& Abraham, R. (1992). Portable infrared pupilloemtry using Pupilscan: relation to somatic and autonomic nerve function in diabetes mellitus. Clin. Auton. Res., 2, 335341.

63. Meeker, M., Du, R., Bachetti, C., Larson, M., Holland, M., \& Manley, G. (2005). Pupil Examination: Validity and Clinical Utility of an Automated Pupillometer. Journal of Neuroscience Nursing, 37(1), 34-40.

64. Piha, S., \& Halonen, J.-P. (1994). Infrared pupillometry in the assessment of autonomic function. Diabetes Research and Clinical Practice, 26, 61-66.

65. Pop, M., Payette, Y., \& Santoriello, E. (2002). Comparison of the pupil card and pupillometer in measuring pupil size. Journal of Cataract Refract Surg, 28(February), 281-288.
66. Taylor, W., Chen, J., Meltzer, H., Gennarelli, T., Kelbch, C., Knowlton, S., ... Marshall, L. (2003). Quantitative pupillometry, a new technology: normative data and preliminary observations in patients with acute head injury. Journal of Neurosurg., 98(January), 205-213.

67. Twa, M., Bailey, M., Hayes, J., Bullimore, M., \& McOptom. (2004). Estimation of pupil size by digital photography. Journal of Cataract Refract Surg, 30(February), 382-289.

68. Neil, H., \& Smith, S. (1989). A simple clinical test of pupillary autonomic function, Correlation with cardiac autonomic function tests in diabetes. Neuro-ophtalmology, 9(4), 237-242.

69. Giakoumaki, S., Hourdaki, E., Grinakis, V., Theou, K., \& Bitsios, P. (2005). Effects of peripheral sympatehtic blockade with dapiprazole on the fear-inhibited light reflex. Journal of Psychopharmacology, 19(2), 139-148.

70. Miciele, G., Tassorelli, C., Martignoni, E., Marcheselli, S., Rossi, F., \& Nappi, G. (1995). Further characterization of autonomic involvement in multiple system atrophy: a pupillometric study. Functional Neurology, 10(6), 273-280.

71. Brismee, J., Gipson, D., Ivie, D., Lopez, A., Moore, M., Matthijs, O., . . Sizer, P. (2006). Interrater Reliability of a Passive Physiological Intervertebral Motion Test in the Mid-Thoracic Spine. Journal of Manipulative and Physiological Therapeutics, 29(5), 368-373.

72. Vleeming, A., Winkel, D., \& Meijer, O. (1984). Weke delen aandoeningen van het bewegingsapparaat (Vol. 1). Utrecht/ Antwerpen: Bohn, Scheltema\& Holkema.

73. Paris, S. (2000). S1 course notes, Chicago.

74. Rickmann, A., Waizel, M., Kazerounian, S., Szurman, P., Wilhelm, H., \& Boden, K. T. (2017). Digital Pupillometry in Normal Subjects. Neuroophthalmology, 41(1), 12-18. doi:10.1 080/01658107.2016.1226345

75. Boev, A., Fountas, K., Karampelas, I., Boev, C., Machinis, T., Feltes, C., . . . Troup, C. (2005). Quantitative pupillometry: normative data in healthy pediatric volunteers. Journal of Neurosurg., 103(December).

76. Merritt, S., Keegan, A., \& Mercer, P. (1994). Artifact Management in pupillometry. Nursing Research, 43(1), 56-59.

77. Haker, E., Egekvist, H., \& Bjerring, P. (2000). Effect of sensory stimulation (acupuncture) on sympathetic and parasympathetic activities in healthy subjects. J Auton Nerv Syst, 79(1), 52-59. Retrieved from https://www.ncbi.nlm.nih. gov/pubmed/10683506

78. Sandberg, M., Lindberg, L. G., \& Gerdle, B. (2004). Peripheral effects of needle stimulation (acupuncture) on skin and muscle blood flow in fibromyalgia. Eur J Pain, 8(2), 163-171. doi:10.1016/S1090-3801(03)00090-9

79. Hu, H. T., Gao, H., Ma, R. J., Zhao, X. F., Tian, H. F., \& Li, L. (2018). Is dry needling effective for low back pain?: A systematic review and PRISMA-compliant meta-analysis. Medicine (Baltimore), 97(26), e11225. doi:10.1097/ MD.0000000000011225

80. Kamali, F., Sinaei, E., \& Morovati, M. (2018). Comparison of Upper Trapezius and Infraspinatus Myofascial Trigger Point Therapy by Dry Needling in Overhead Athletes With Unilateral Shoulder Impingement Syndrome. J Sport Rehabil, 1-24. doi:10.1123/jsr.2017-0207

81. Liu, L., Huang, Q. M., Liu, Q. G., Thitham, N., Li, L. H., Ma, Y. T., \& Zhao, J. M. (2018). Evidence for Dry Needling in the Management of Myofascial Trigger Points Associated With Low Back Pain: A Systematic Review and Meta-Analysis. Arch Phys Med Rehabil, 99(1), 144-152 e142. doi:10.1016/j. apmr.2017.06.008 
82. Nunez-Cortes, R., Cruz-Montecinos, C., Vasquez-Rosel, A., Paredes-Molina, O., \& Cuesta-Vargas, A. (2017). Dry Needling Combined With Physical Therapy in Patients With Chronic Postsurgical Pain Following Total Knee Arthroplasty: A Case Series. J Orthop Sports Phys Ther, 47(3), 209-216. doi:10.2519/ jospt.2017.7089

83. Perreault, T., Dunning, J., \& Butts, R. (2017). The local twitch response during trigger point dry needling: Is it necessary for successful outcomes? J Bodyw Mov Ther, 21(4), 940-947. doi:10.1016/j.jbmt.2017.03.008

84. Tough, E. A., White, A. R., Cummings, T. M., Richards, S. H., \& Campbell, J. L. (2009). Acupuncture and dry needling in the management of myofascial trigger point pain: a systematic review and meta-analysis of randomised controlled trials. Eur J Pain, 13(1), 3-10. doi:10.1016/j.ejpain.2008.02.006

85. Gattie, E., Cleland, J. A., \& Snodgrass, S. (2017). The Effectiveness of Trigger Point Dry Needling for Musculoskeletal Conditions by Physical Therapists: A Systematic Review and Meta-analysis. J Orthop Sports Phys Ther, 47(3), 133-149. doi:10.2519/jospt.2017.7096

86. Gerber, L. H., Sikdar, S., Aredo, J. V., Armstrong, K., Rosenberger, W. F., Shao, H., \& Shah, J. P. (2017). Beneficial Effects of Dry Needling for Treatment of Chronic Myofascial Pain Persist for 6 Weeks After Treatment Completion. PM R, 9(2), 105-112. doi:10.1016/j.pmrj.2016.06.006

87. Hsieh, Y., Kao, M., Kuan, T., Chen, S., Chen, J., \& Hong, C. (2007). Dry Needling to a Key Myofascial Trigger Point May Reduce the Irritability of Satellite MTrPs. Am. J. Phys. Med. Rehabil., 86(5), 398-403.

88. Rhudy, J., Williams, A., McCabe, K., Thu, M., Nguyen, V., \& Rambo, P. (2005). Affective modulation of nociception at spinal and supraspinal levels. Psychophysiology, 42, 579-587.
89. Van Cranenburgh, B. (1989a). Inleiding in the toegepaste neurowetenschappen (Vol. 3). Lochem: Uitgeversmaatschappij de Tijdstroom.

90. Wang, G., Gao, Q., Li, J., Tian, Y., \& Hou, J. (2016). Impact of Needle Diameter on Long-Term Dry Needling Treatment of Chronic Lumbar Myofascial Pain Syndrome. Am J Phys Med Rehabil, 95(7), 483-494. doi:10.1097/PHM.0000000000000401

91. Martin-Pintado-Zugasti, A., Mayoral Del Moral, O., Gerwin, R. D., \& Fernandez-Carnero, J. (2018). Post-needling soreness after myofascial trigger point dry needling: Current status and future research. J Bodyw Mov Ther, 22(4), 941-946. doi:10.1016/j. jbmt.2018.01.003

92. Martin-Pintado-Zugasti, A., Rodriguez-Fernandez, A. L., \& Fernandez-Carnero, J. (2016). Postneedling soreness after deep dry needling of a latent myofascial trigger point in the upper trapezius muscle: Characteristics, sex differences and associated factors. J Back Musculoskelet Rehabil, 29(2), 301308. doi:10.3233/BMR-150630

93. Ellermeier, W., \& Westphal, W. (1995). Gender differences in pain ratings and pupil reactions to painful pressure stimuli. Pain, $61,435-439$. 